\title{
Experimental investigation of immiscible water-alternating-gas injection in ultra-high water-cut stage reservoir
}

\author{
Debin Kong ${ }^{1,2} *$, Yubao Gao ${ }^{1,2}$, Hemanta Sarma ${ }^{3}$, Yiqiang $\mathrm{Li}^{4}$, Hu Guo ${ }^{4}$, Weiyao Zhu ${ }^{1,2}$ \\ ${ }^{1}$ School of Civil and Resources Engineering, University of Science and Technology Beijing, Beijing 100083, P. R. China \\ ${ }^{2}$ Institute of Applied Mechanics, University of Science and Technology Beijing, Beijing 100083, P. R. China \\ ${ }^{3}$ Department of Chemical and Petroleum Engineering, University of Calgary, Calgary T2N 1N4, Canada \\ ${ }^{4}$ State Key Laboratory of Petroleum Resources and Prospecting, China University of Petroleum, Beijing 102249, P. R. China
}

Keywords:

Water-alternating-gas

microscopic visualization experiments

residual oil mobilizing

force balance analysis

trapped-gas saturation

Cited as:

Kong, D., Gao, Y., Sarma, H., Li, Y., Guo, H., Zhu, W. Experimental investigation of immiscible water-alternating-gas injection in ultra-high water-cut stage reservoir.

Advances in Geo-Energy Research, 2021, 5(2): 139-152, doi:

10.46690/ager.2021.02.04

\begin{abstract}
:
Water-alternating-gas (WAG) injection is recommended as a means of improving gas mobility control. This paper describes a series of coreflood tests conducted to investigate the potential for continuous gas injection and WAG injection in ultra-high water-cut saline reservoirs. The mechanisms of immiscible water-alternating-nitrogen injection on residual oil distribution are analyzed, and pore-scale analysis is conducted. The effect of injection parameters on residual oil distribution and recovery efficiency is also evaluated. Coreflood results show that tertiary oil recovery efficiency is significantly higher using WAG injection than continuous gas injection during the ultra-high water-cut period. Porescale visualization illustrates the movement of gas through the waterflooded channels into the pore space previously occupied by water and residual oil, which then becomes trapped. Injected gas breaks the force balance of microscopic residual oil and reduces residual oil saturation. This mobilizes the displaced/collected residual oil into large waterfilled pores and blocks several water channels. WAG flooding can decrease free-gas saturation and increase trapped-gas saturation significantly, resulting in decreased relative permeabilities of gas and water. The experimental results indicate that appropriate WAG design parameters could enhance recovery by $15.62 \%$ when the injected pore volume of water and gas in the cycle is $0.3 \mathrm{PV}$ at a gas/water injection ratio of $2: 1$. The results from this study will allow researchers and reservoir engineers to understand and implement immiscible WAG injection as an enhanced oil recovery method in ultra-high water-cut stage reservoirs.
\end{abstract}

\section{Introduction}

Enhanced oil recovery (EOR) methods in the ultra-high water-cut period include chemical flooding, thermal oil recovery, and gas flooding (Liu et al., 2020). At present, the most popular EOR method for saline reservoirs is water flooding (You et al., 2018; You et al., 2019; Zhang et al., 2019), as it is difficult to use chemical flooding in the high salinity environment of reservoirs. Besides water injection, there is no suitable EOR method for saline reservoirs (Sun et al., 2016; Yang et al., 2018; Kong et al., 2019). Gas has a large molecular spacing and can easily be compressed or expand. It can enter the pore spaces that may previously have been inaccessible during water flooding at higher pressure, thus expanding the swept volume. The injected gas can become trapped in the pores, causing the water phase permeability to decrease and achieving the purpose of water control (Valeev and Shevelev, 2017; Itriago et al., 2018; Janssen et al., 2018).

Carbon dioxide, nitrogen, hydrocarbon gas, and mixed gas are commonly used in gas injection. If implemented properly, gas injection is an economical and effective tertiary oil recovery method (Li et al., 2016; Singh, 2018; Kong et al. 2020). Due to the heterogeneities of the oil-bearing layer and the existence of fractures, early gas breakthroughs often occur during gas flooding, reducing the effectiveness of this approach. Gas injection in the water-alternating-gas (WAG) mode can effectively suppress early gas breakthroughs, delay the gas rafting time, and improve the gas flooding effect (Ramachandran et al., 2010; Afzali et al., 2018; Janssen et al.,

\section{Yandy} Scientific Press

${ }^{*}$ Corresponding author.

E-mail address: kongdb@ustb.edu.cn (D. Kong); gyubao1996@163.com (Y. Gao); liyiqiang@cup.edu.cn (Y. Li);

hemanta.sarma@ucalgary.ca (H. Sarma); truetutors@126.com (H. Guo); weiyaook@sina.com (W. Zhu). 2207-9963 () The Author(s) 2021.

Received February 22, 2021; revised March 15, 2021; accepted March 16, 2021; available online March 19, 2021.
} 
2020). In the WAG flooding process, the injected gas has a high microscopic oil displacement efficiency, and the injected water has a high macroscopic swept volume. The combined injection gas and injected water can significantly enlarge the swept volume and adjust the fluid injection profile.

After gas is injected into the reservoir, the seepage state changes from the original oil-water two-phase seepage to a three-phase oil-gas-water seepage. In the middle and late stages of water flooding, the relative permeability of water in the porous medium is relatively high, the flow resistance is small, and the water easily flows through channels. After the gas-water alternation is used to inject gas, the relative permeability of the water phase is greatly reduced, and the flow resistance increases. When that happens, the possibility of water channeling is greatly reduced (Shahverdi et al., 2013; Afzali et al., 2020). At the same time, due to the presence of the water phase, the relative permeability of the gas phase becomes much lower than that during gas flooding. Thus, gas fingering can be controlled, the gas front becomes more stable (which effectively prolongs the time required for the gas to break through to the oil well), and the sweep efficiency improves; in turn, this effectively improves the recovery factor. The WAG flooding technology has been tested and applied in many oil fields around the world, and has been found to significantly reduce the water saturation and increase the recovery rate by up to $10 \%$ (Christensen et al., 2001; Afzali et al., 2018; Liu et al., 2020).

To date, most scholars have focused on the flow control ability of WAG flooding. Physical simulations and pore network simulations are widely used in the study of microscopic seepage laws (Heiba et al., 1984; Oren et al., 1992; Oren, 1994; Oren and Pinczewski, 1996; Pereira et al., 1996; Sohrabi et al., 2004; Wang et al., 2019; Zhu et al., 2019; Liu et al., 2020; Wang et al., 2020). Glass-etched models and highdefinition imaging technology are used to observe the fluid seepage laws and distribution characteristics of reservoirs of different wettability during the WAG flooding process. Compared with single-gas flooding or water flooding, the recovery efficiency is higher and the oil displacement effect is better with WAG flooding. The reservoir wettability has a significant influence on the oil displacement effect. Oil-wet reservoirs have the highest recovery rate, and water-wet reservoirs have the lowest; mixed-wet reservoirs are somewhere in the middle. The effect of oil displacement is also influenced by the cumulative injection volume. The higher the cumulative volume of fluid injected, the higher is the recovery factor.

The WAG process includes drainage and imbibition, that is, the process of alternating displacement between wetting and non-wetting phases (Ghomian et al., 2008; Fatemi and Sohrabi, 2012; Khorsandi et al., 2017; Afzali et al., 2020). The wetting hysteresis in this process affects the law of multiphase flow, which corresponds to wetting-phase saturation (saturation path and saturation history). The complexity is associated with the wetting-phase relative permeability, corresponding to the wetting-phase saturation at which flow reversal takes place (Keller et al., 1997; Blunt, 1999; Akervoll et al., 2000; DiCarlo et al., 2000; Mohammad and Blunt, 2004; Shahverdi et al., 2011; Zuo et al., 2013). The relative permeability of the three phases has implications for the dissolution and capillary trapping mechanisms, and is significant in terms of trappedgas saturation affecting the imbibition-relative permeability of the wetting phase (Khorshidian et al., 2017; Afzali et al., 2018; Long et al., 2018; Afzali et al., 2020; Rücker et al., 2020) Core flooding experiments have also been conducted to investigate the performance of WAG flooding (Kulkarni and Rao, 2005; Guo et al., 2012; Fatemi and Sohrabi, 2013; Motealleh et al., 2013; Khanifar et al., 2015; Hoare and Coll, 2018). The characteristics of the injection capacity and oil recovery performance at different injection rates, slug sizes, and gaswater ratios have been investigated using one-, two-, and threedimensional cores. The experimental results show that the injection capacity decreases as the gas/water ratio and slug size decrease. WAG flooding can improve the microscopic oil displacement efficiency and increase the formation pressure. However, only a few researchers have studied the interaction between the rock-fluid, water, and gas during WAG flooding.

In this paper, a medium-high-permeability and saline reservoir at an ultra-high water-cut is studied. The research method combines core displacement experiments and microscopic visualization experiments. The potential and mechanism of continuous gas injection (CGI) and non-miscible WAG injection for the water-flooding of residual oil in the saline reservoir are investigated by core flooding experiments. The effect of the injection parameters (injection pore volume (IPV) $(\mathrm{W}+\mathrm{G})$ of each cycle and the injection ratio of gas to water) is also analyzed. The microscopic residual oil characteristics at different displacement stages are observed by microscopic visualization experiments, and the residual oil saturation of different types is calculated using image processing techniques. The gasliquid-rock interaction in the process of water injection and gas injection is analyzed at the pore scale, and the mobilizing mechanism of different types of residual oil is explained using force analysis.

\section{Experimental method and procedures}

\subsection{Experimental materials}

The simulated oil is a mixture of kerosene and transformer oil with a viscosity of $1.82 \mathrm{mPa} \cdot \mathrm{s}$ and a density of $0.78 \mathrm{~g} / \mathrm{cm}^{3}$ at a reservoir temperature of $80{ }^{\circ} \mathrm{C}$. The salinity of the forma-

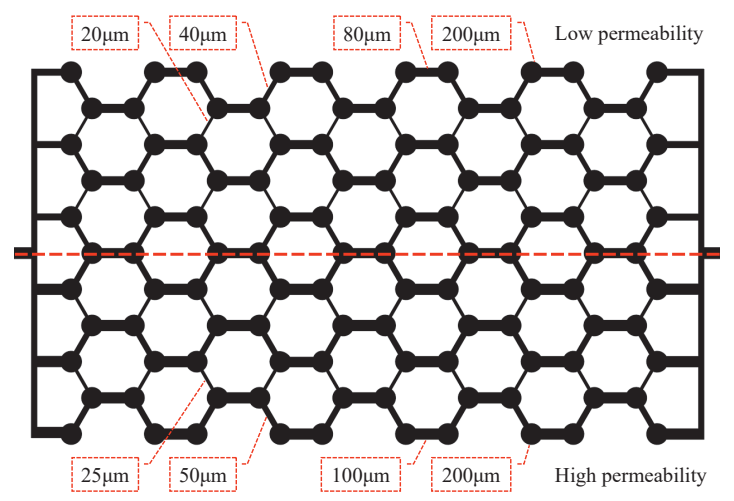

Fig. 1. Schematic diagram of the pore network in the ball-and-stick model. 
Table 1. Properties of natural outcrop sandstone cores used in the coreflood experiments.

\begin{tabular}{lllllll}
\hline & Procedure & Permeability $\left(\times 10^{-3} \mu \mathrm{m}^{2}\right)$ & Porosity $(\%)$ & Length $(\mathrm{cm})$ & Diameter $(\mathrm{cm})$ & Pore volume $\left(\mathrm{cm}^{3}\right)$ \\
\hline 1 & WF+CGI & 282.75 & 18.13 & 28.91 & 2.57 & 27.19 \\
2 & WF+WAG & 241.27 & 20.73 & 30.12 & 2.58 & 32.64 \\
3 & WF+WAG & 241.27 & 19.43 & 30.12 & 2.58 & 30.60 \\
4 & WF+WAG & 237.61 & 19.43 & 29.91 & 2.58 & 30.38 \\
5 & WF+WAG & 257.13 & 18.13 & 31.33 & 2.57 & 29.47 \\
6 & WF+WAG & 264.45 & 19.43 & 31.33 & 2.58 & 31.82 \\
7 & WF+WAG & 274.21 & 18.13 & 30.12 & 2.58 & 28.55 \\
8 & WF+WAG & 279.09 & 18.13 & 30.12 & 2.58 & 28.55 \\
\hline
\end{tabular}

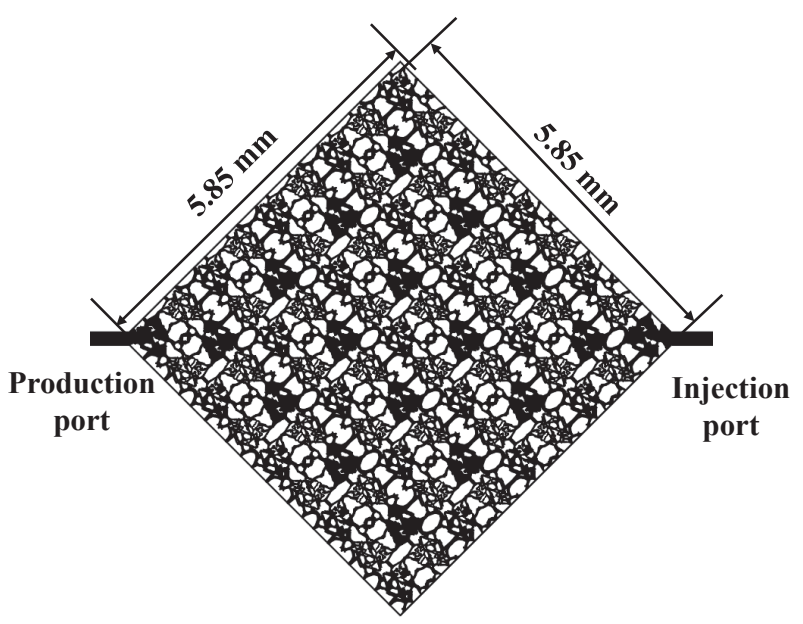

(a)

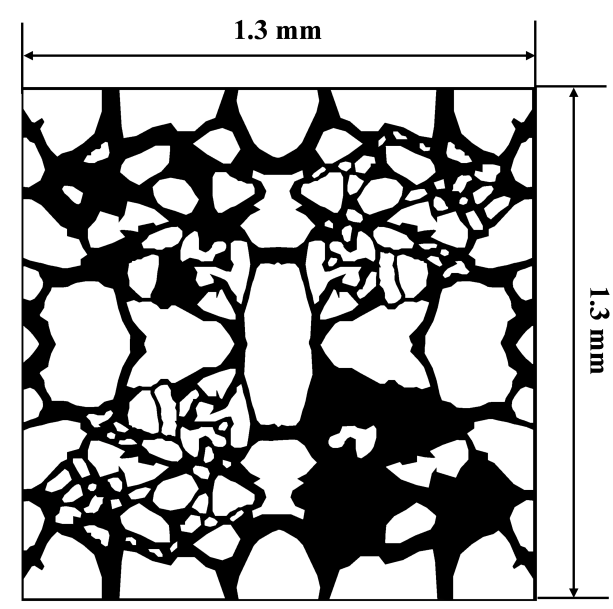

(b)

Fig. 2. (a) Pore network of micromodel; (b) Repeated pattern in the pore network.

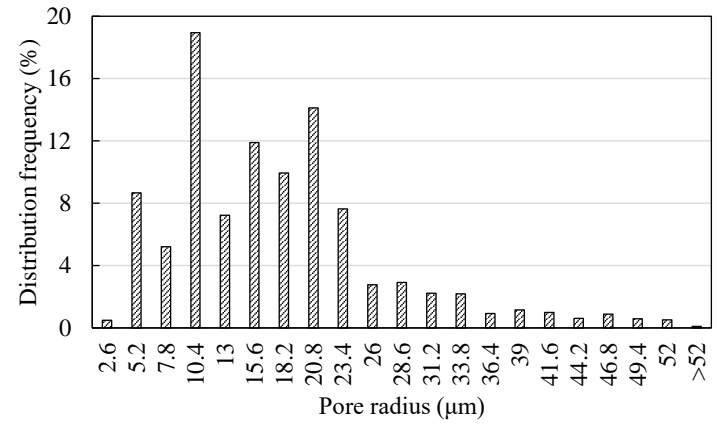

Fig. 3. Pore radius of the micromodel.

tion water is $2.4 \times 10^{5} \mathrm{mg} / \mathrm{L}$; a NaCl solution of $2.4 \times 10^{5} \mathrm{mg} / \mathrm{L}$ is used to simulate the water in the experiments. The gas is nitrogen $\left(\mathrm{N}_{2}\right)$ with a purity of $99.99 \%$.

The experimental core is a natural outcrop sandstone with a permeability of $250 \times 10^{-3} \mu \mathrm{m}^{2}$ and a porosity of $19.5 \%$. The cores measure $30 \mathrm{~cm}$ in length and $2.5 \mathrm{~cm}$ in diameter. The physical properties of the cores are listed in Table 1.

A micromodel fabricated by oil-wet polydimethylsiloxane (PDMS) is used in the pore-scale visualization experiments. There are two kinds of experiment models, a ball-and-stick pore network model and a simulation pore network model based on the cast thin slice image. The model material is PDMS polymer, and the wetting angle between the oil and PDMS is $128.3^{\circ}$. As shown in Fig. 1, the ball-andstick pore network model is divided into two regions, one of high permeability and one of low permeability, by the main flow line (above the red line is the low permeability region) and the coordination number of each region is 3 . The difference between high and low permeability in the reservoir is simulated by changing the throat size. The seepage area measures $6.5 \mathrm{~mm}$ (length) $\times 3.5 \mathrm{~mm}$ (width) $\times 25 \mu \mathrm{m}$ (depth), and consists of 110 pores and 161 throats. The pore diameters are all $200 \mu \mathrm{m}$. The three throats connected to the pores in the low permeability area (above the red line) have widths of 80 $\mu \mathrm{m}, 40 \mu \mathrm{m}$, and $20 \mu \mathrm{m}$, respectively; those connected to the pores in the high permeability area have widths of $100 \mu \mathrm{m}$, $50 \mu \mathrm{m}$, and $25 \mu \mathrm{m}$, respectively.

The pore network of the micromodel is formed by repeating a smaller pattern that was designed based on a thin conglomerate section, as shown in Fig. 2(b). The pore radius of the micromodel ranges from $2-52 \mu \mathrm{m}$, as shown in Fig. 3 . The pore distribution of the micromodel is similar to that of the real cores, so it can be used to study the microscopic remaining oil and represent the real cores. 
Table 2. Experimental scheme of tertiary gas injection core flooding experiment.

\begin{tabular}{llllll}
\hline Experiment & Process & Gas flow rate, $\mathrm{mL} / \mathrm{min}$ & Liquid flow rate, $\mathrm{mL} / \mathrm{min}$ & IPV & WAG ratio \\
\hline 1 & WF+CGI & 0.15 & $/$ & $/$ & $/$ \\
2 & WF+WAG & 0.15 & 0.3 & 0.3 & $2: 1$ \\
3 & WF+WAG & 0.15 & 0.3 & 0.2 & $2: 1$ \\
4 & WF+WAG & 0.15 & 0.3 & 0.4 & $2: 1$ \\
5 & WF+WAG & 0.15 & 0.3 & 0.5 & $2: 1$ \\
6 & WF+WAG & 0.15 & 0.3 & 0.3 & $1: 2$ \\
7 & WF+WAG & 0.15 & 0.3 & 0.3 & $1: 1$ \\
8 & WF+WAG & 0.15 & 0.3 & 0.3 & $3: 1$ \\
\hline
\end{tabular}

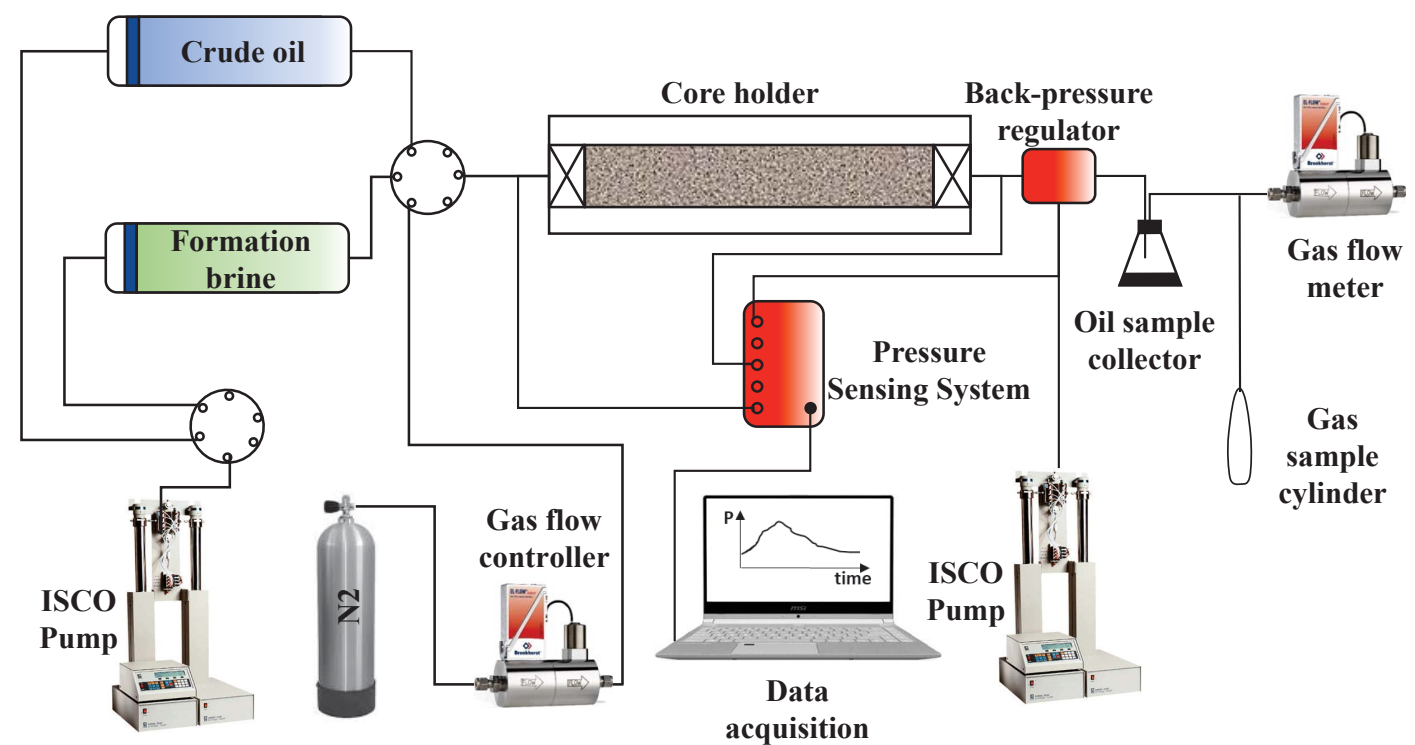

Fig. 4. Experimental setup diagram of $\mathrm{N}_{2}$ core flooding.

\subsection{Experimental procedures}

\subsubsection{Tertiary gas injection core flooding experiment}

Natural outcrop sandstone with the same physical properties was used in the experiments. The first experiment used water flooding to achieve the ultra-high water-cut stage, and then gas injection was carried out to perform both $\mathrm{N}_{2}$-CGI and $\mathrm{N}_{2}$-WAG experiments, as per the experimental scheme in Table 2.

The experimental procedures were as follows:

1) The core was evacuated, and then the simulated water was injected at a rate of $0.1 \mathrm{~mL} / \mathrm{min}$ to obtain the pore volume and the effective water-phase permeability. The simulated oil was injected at $0.05 \mathrm{~mL} / \mathrm{min}$ at $80^{\circ} \mathrm{C}$ until the water was no longer produced. This step helped obtain the original oil saturation.

2) The core was placed in the core holder, and the pressure at the outlet was controlled at $2 \mathrm{MPa}$ through the backpressure valve. The formation water was injected at a rate of $0.15 \mathrm{~mL} / \mathrm{min}$ until the water-cut at the outlet reached 98\% (see Fig. 4).

3) An $\mathrm{N}_{2}$-CGI experiment was carried out after the water flooding. A gas mass flow controller was used to control the gas injection rate under the reservoir condition to 0.15 $\mathrm{mL} / \mathrm{min}$, and the experiment was stopped when the gas/oil ratio of the outlet production exceeded $3000 \mathrm{~m}^{3} / \mathrm{m}^{3}$. Experimental data such as the displacement pressure difference, liquid production, and gas production were recorded.

4) An $\mathrm{N}_{2}$-WAG experiment after water flooding was then conducted using the same core with similar physical properties. Steps 1 and 2 were repeated. When the watercut of the core outlet reached $98 \%$, the gas and water were alternately injected into the core. The detailed injection scheme is summarized in Table 2. The experiment was stopped after five cycles of injection. Experimental data such as the displacement pressure difference, liquid production, and gas production were recorded.

\subsubsection{Pore-scale tertiary gas injection visualization experiment}

The experimental setup is shown in Fig. 5. It includes a micro-flow control system that provides constant pressure during water flooding and gas flooding, a microscope (Zeiss- 

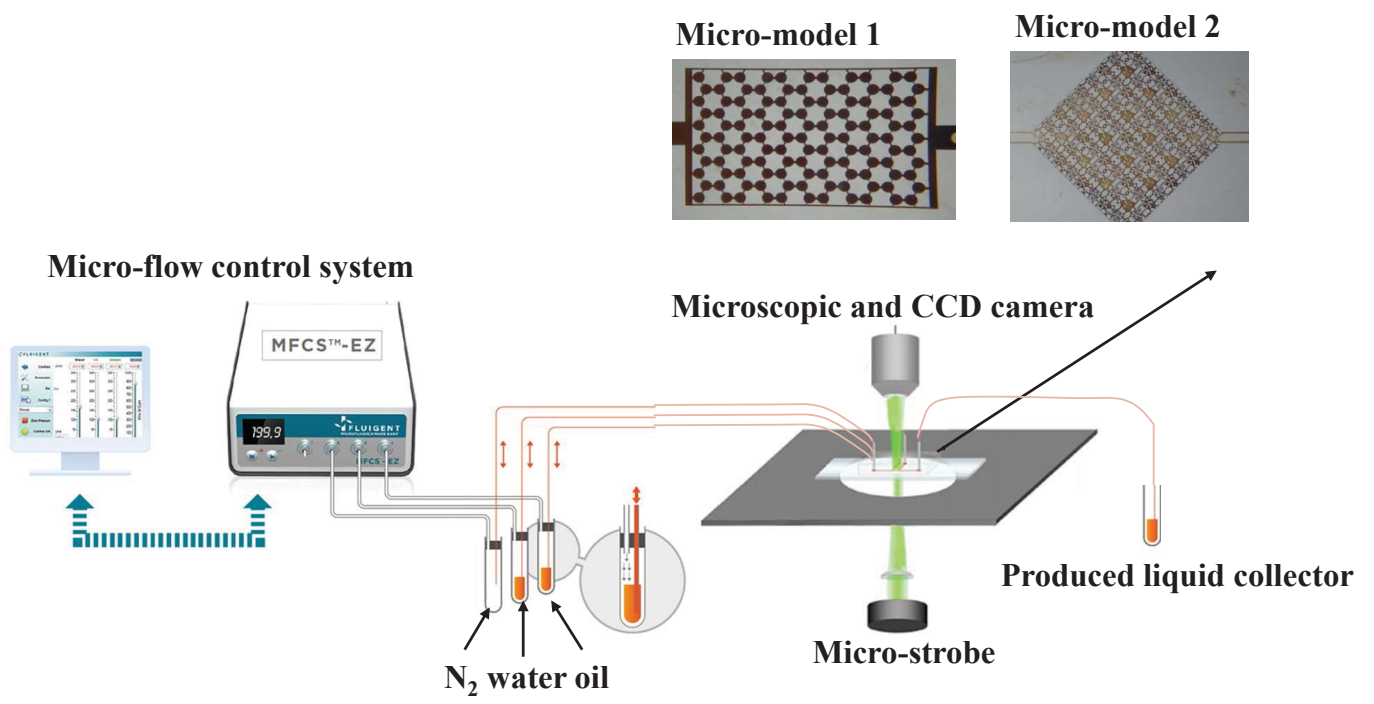

Fig. 5. Experimental setup diagram of pore-scale visualization experiment.

Discovery Stereo V12) for capturing microscopic images, and a digital video recorder (Sony-A7S2) for recording the flow process. The experimental procedures of the pore-scale experiment were as follows:

1) The micromodel was injected with crude oil using a syringe. The model was then placed under the microscope and connected as shown in Fig. 3.

2) The formation water was injected at a constant injection pressure of $5 \mathrm{kPa}$ until the outlet did not produce oil.

3) The $\mathrm{N}_{2}$ was injected at a constant injection pressure of 1.5 $\mathrm{kPa}$ after water flooding until the outlet did not produce oil.

4) The water and $\mathrm{N}_{2}$ were alternately injected into the micromodel (water injection pressure: $6.5 \mathrm{kPa} ; \mathrm{N}_{2}$ injection pressure: $2 \mathrm{kPa}$ ). Each gas slug and water slug continued for $30 \mathrm{~min}$, and the experiment was stopped after the second round of water injection.

5) The displacement dynamics were observed with the microscope and recorded by the camera during the flooding process.

\section{Results and discussion}

\subsection{Tertiary gas injection core flooding experiment}

The effect of the tertiary gas injection scheme can be determined by comparing Case 1 and Case 2. Fig. 6 shows that more than $60 \%$ of the residual oil remains in the formation after water flooding. Both $\mathrm{N}_{2}$-CGI and $\mathrm{N}_{2}$-WAG can improve the oil recovery performance after water flooding. The gas breakthrough during $\mathrm{N}_{2}$-CGI injection began when the injected total pore volume was $0.16 \mathrm{PV}$; in the case of $\mathrm{N}_{2}$-WAG, this increased to $0.28 \mathrm{PV}$. Due to the early gas breakthrough, $\mathrm{N}_{2}$ CGI increased oil recovery by only $5.27 \%$, whereas $\mathrm{N}_{2}$-WAG increased oil recovery by $15.62 \%$. Fig. 7 shows that $\mathrm{N}_{2}$-WAG can significantly increase the displacement pressure difference (up to double that after water flooding), while the pressure of

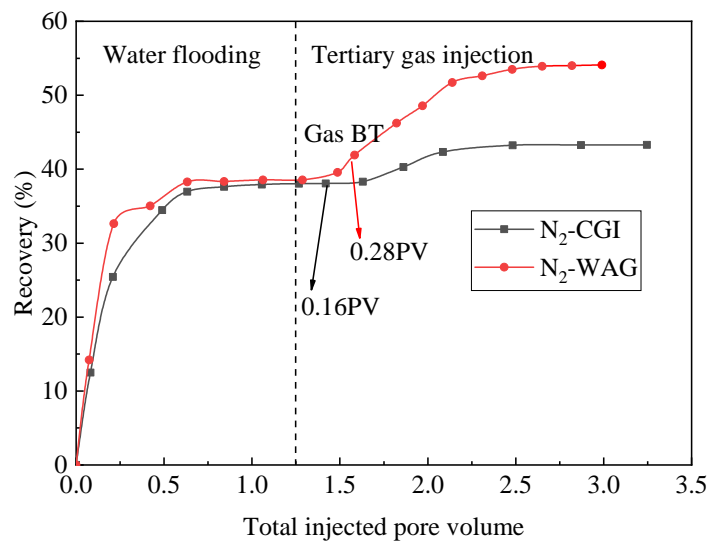

Fig. 6. Effect on oil recovery of different tertiary gas injection schemes.

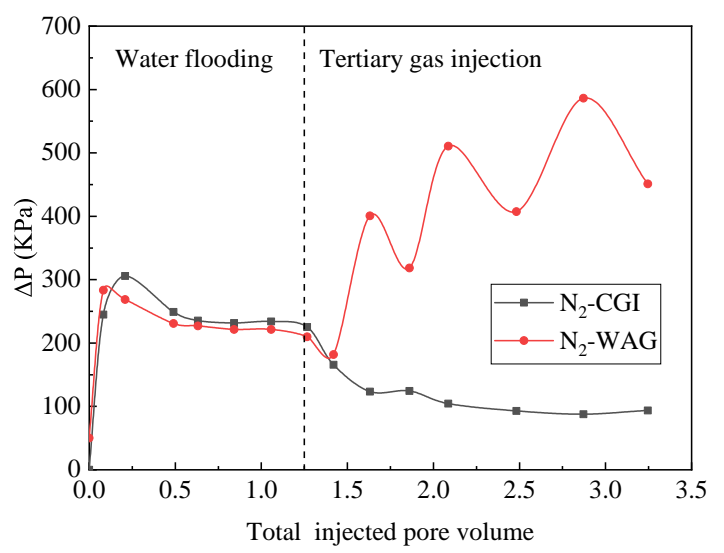

Fig. 7. Effect on displacement pressure of different tertiary gas injection schemes.

$\mathrm{N}_{2}$-CGI drops sharply. An increase in pressure can cause gas and water to enter the pore space occupied by residue oil, thereby increasing the microscopic sweep efficiency. 


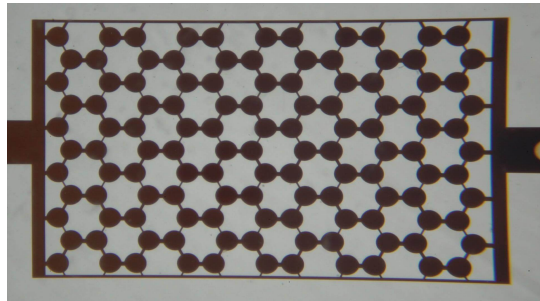

(a)

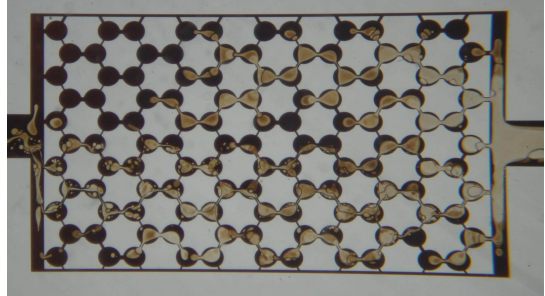

(d)

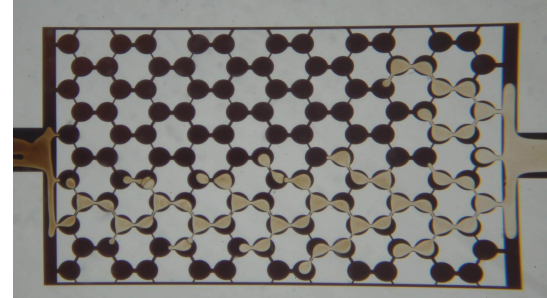

(b)

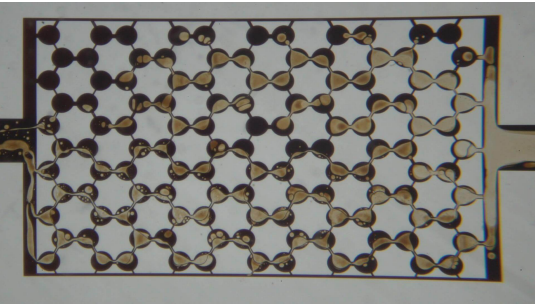

(e)

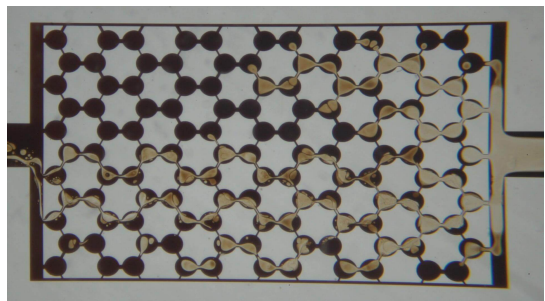

(c)

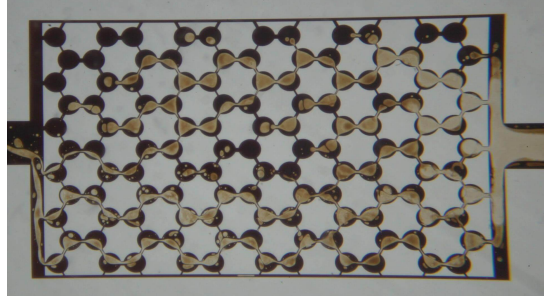

(f)

Fig. 8. Microscopic experimental real-time image of gas flooding in Model 1 (a) Saturated oil state; (b) after water flooding at low injection rate; (c) after water flooding at high injection rate; (d) after first round of gas injection; (e) after first round of water injection; (f) after second round of gas injection (fluid is flowing from left to right).

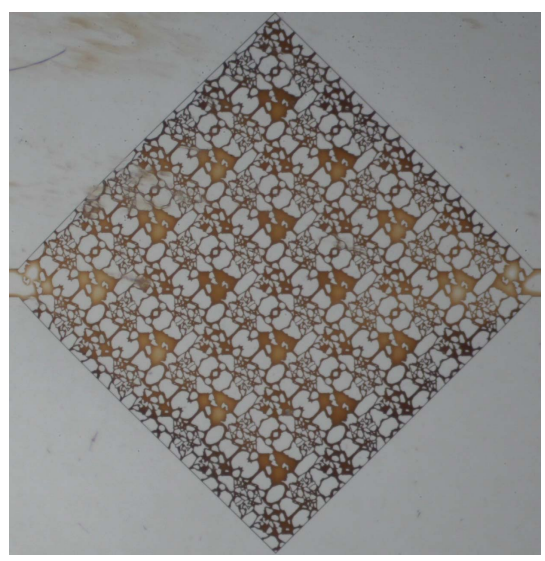

(a)

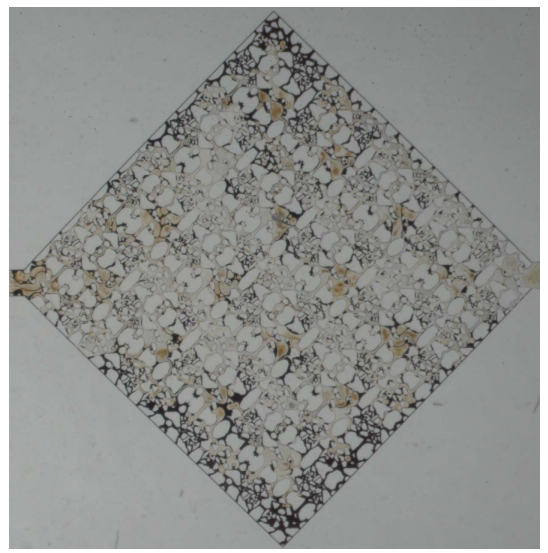

(d)

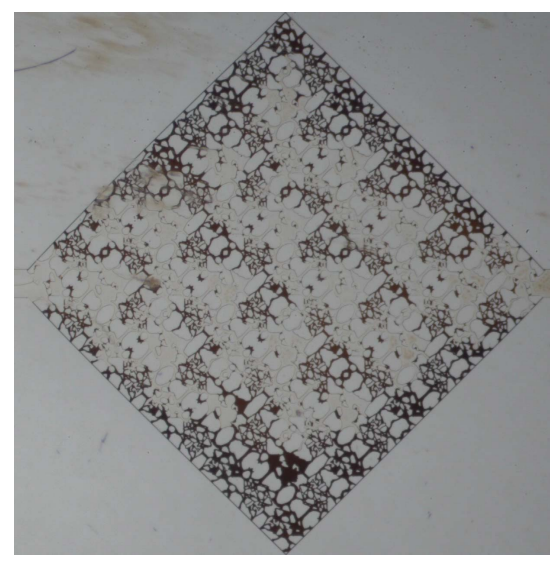

(b)

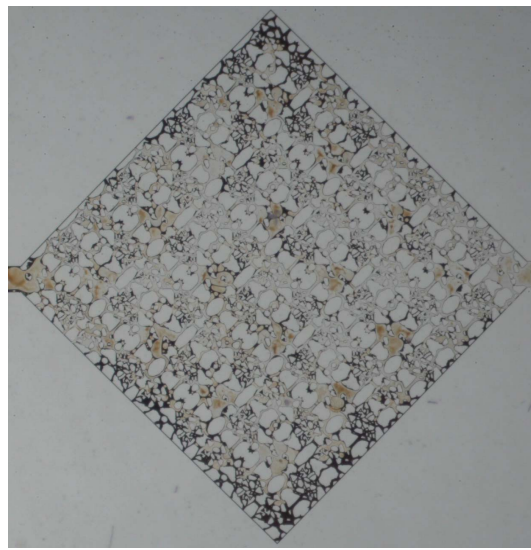

(e)

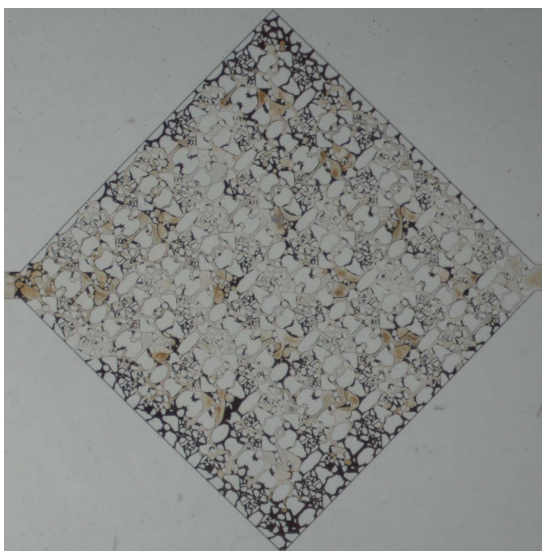

(c)

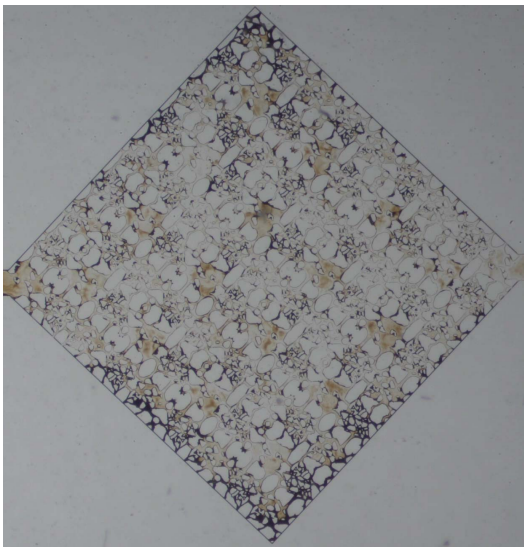

(f)

Fig. 9. Microscopic experimental real-time image of gas flooding in Model 2 (a) Saturated oil state; (b) after water flooding; (c) after first round of gas injection; (d) after first round of water injection; (e) after second round of gas injection; (f) after second round of water injection (fluid flowing from left to right). 


\subsection{Pore-scale tertiary gas injection visualization experiment}

\subsubsection{Distribution characteristics of microscopic residual} oil

The overall characteristics of the residual oil at different displacement stages after water flooding with gas injection and alternate water-gas injection are shown in Figs. 8 and 9.

The PDMS material is oil-wet, and the surface of the pore throat is more attractive to oil than water. Pores and throat surfaces with a larger radius find it easier to absorb oil (Xu et al., 2020). The oil closer to the surface of the pore throat is more attractive to the solid surface, so the surface of the pore throat becomes covered by an oil film. However, the oil film thickness of different pore throats will vary, and may even be different around the same pore throat.

It can be seen from Figs. 8(b), 8(c) and 9(b) that the injected water first invades the main streamline of the macropore, entering the central pores. After entering these pores, it flows along the central part of the pores, displacing the crude oil in the central part. At the same time, an oil film of varying thickness remains on the pore wall. This displacement phenomenon can be referred to as the "intrusion" mechanism. As the water injection proceeds, the injected water breaks through and the mainstream forms the dominant water channel. At this time, it is difficult to mobilize the residual oil dispersed in the small pores. The injected water cannot enter the pores because the capillary resistance in the throat is very large. The oil will remain in the throat in the form of an oil column, so it is difficult to sweep the oil in the larger pores controlled by a small throat. This is because the porous medium is oil-wet, and there is a cluster of residual oil surrounded by small pores. Increasing the injection rate can expand the swept volume, but the capacity is limited.

Figs. 8(d) and 9(c) show the primary gas injection stage after water flooding. The gas enters the main water channel with small flow resistance. Subsequently, the continuous gas disperses into bubbles, and the Jamin effect increases the capillary pressure as the bubbles pass through the throat, causing the subsequent gas flow direction to change (Wang et al., 2020). Some of the gas gathers the membrane oil adsorbed on the wall and the scattered oil droplets in the large pores into an oil film, whereas other gas pushes the residual oil bound in the small pores into the large pores. Compared with water flooding, gas flooding slightly increases the swept area, thus improving the oil displacement efficiency.

Figs. 8(e)-8(f) and 9(d)-9(f) show the water-gas alternation process after water flooding. Water is injected into the model after gas injection. and flows along the dominant channel of water flooding. This part of the injected water pushes the oil gathered in the large pores in the gas injection stage into the production well. At the same time, the subsequent injection of water captures the gas in the pores, thereby reducing the flow space and further expanding the swept volume.

The adsorption force of the pore throat wall with respect to crude oil is larger than that for water because the reservoir is oil-wet. As a non-wet phase, water preferentially occupies the central part of the large pore throat. As the injected gas is also a non-wet phase, it also preferentially occupies the central part of the large pore throat. However, the injected water has occupied the central axis of the large pore throat, and the interfacial tension of gas and water is much larger than that of gas and oil. Therefore, the injected gas is more inclined to displace the residual oil near the wall, and is separated from the oil film between the injected water and the injected gas. In addition, the injected gas displaces the residual oil in pore throats with a slightly smaller radius that is not displaced by the injected water. Hence, the injected gas and water squeeze the oil in the central axis of large pore throats onto small pore throats and the pore throat walls. The crude oil in the macropore throats is easily displaced by gas and water.

In the macropore throats, the oil phase exists on the wall of the pore throat in the form of oil film. In addition, there is a layer of oil film on the gas-water interface. The thickness and distribution of the oil film are related to the shape of the gaswater interface. The oil film is thicker where the curvature of the gas-water interface is large, and thinner where the curvature of the gas-water interface is small. When the airwater interface flows forward, the oil film on the interface also flows forward. In areas of gas-water-solid three-phase intersection, a thick oil film gathers. This shows that the oil on the pore walls tends to gather at the intersection of the gas, water, and solid. In the process of gas-water alternation flooding, this intersection plays the role of gathering oil. The three-phase gas-water-solid gathers oil, and the gas-water interface connects oil. The combination of the two makes the oil phase flow better, so as to displace more residual oil out of the pores and improve oil recovery.

\subsubsection{Analysis of mobilization mechanism of microscopic residual oil}

Due to the complex pore structure of reservoir rock and different wettability of each position, the residual oil has a variety of occurrence states. These can be divided into film residual oil, columnar residual oil, island residual oil, clusters residual oil, and dead-end (corner) residual oil (Wang et al., 2019; Xu et al., 2020). Film residual oil comes from incomplete washing-away by water flooding. Columnar residual oil, island residual oil, clusters residual oil, and dead-end (corner)

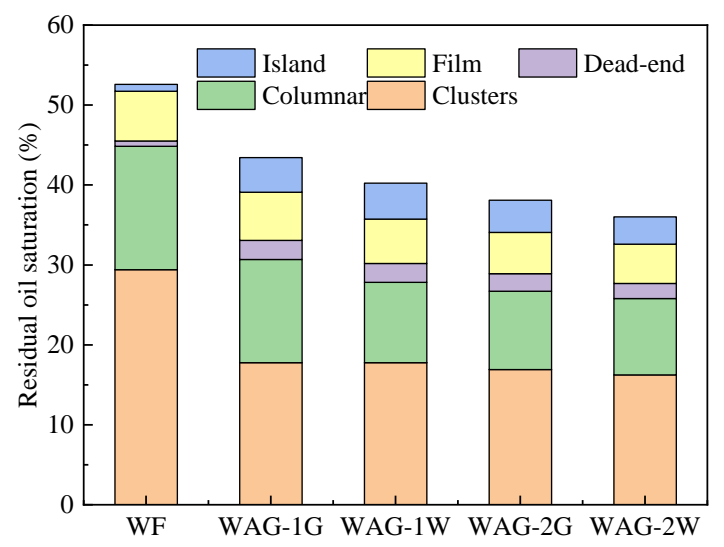

Fig. 10. Change of microscopic remaining oil saturation during WAG flooding. 
residual oil are formed by the retention of microscopic unaffected areas. The variation of several residual oil types in different displacement stages of the core etching model is shown in Fig. 10.

The clusters and columnar residual oil saturation are highest after water flooding, and the film residual oil saturation is higher than that of dead-end and island residual oil because the porous media is oil-wet. After the first round of gas flooding, the clusters and columnar residual oil saturation are significantly reduced, while the other types of residual oil saturation are obviously increased. In the process of gas flooding, the swept volume becomes larger and the cluster residual oil is dispersed and transformed into other types of residual oil. The columnar residual oil saturation decreases after the first round of water flooding. After the second round of WAG, the film, dead-end, and island residual oil have been decreased, and the cluster and columnar residual oil saturation have changed slightly.

The microscopic oil displacement mechanism of gas flooding can be determined by analyzing the force balance of residual oil before and after gas injection.

\section{(1) Film residual oil mobilization mechanism}

The film residual oil is mainly distributed on the rock wall. There is a strong interaction between the rock and the film residual oil, which cannot be separated from the rock wall by the shear stress of the injected water. It is assumed that the oil film is sheared by the water in a layer-by-layer process, whereby it peels off the rock wall. At this time, the oil film surface is mainly subjected to interfacial tension, the shear stress of the injected water on the oil film, and the viscous shear stress between the retained oil film and the peeled oil film, as shown in Fig. 11.

Generally, the thickness of the oil film is small, and it can be considered that the front and rear wetting angles are the same. After water flooding, the combined force of the oilwater interfacial tension $F_{\sigma}$ in the direction of movement is zero. The shear stress $F_{\tau w}$ of the injected water on the oil film is related to the flow rate of the injected water, the oil viscosity, and the thickness and length of the oil film. The viscous shear force between the retained oil film and the peeled oil film is related to the oil viscosity and the length of the oil film.

After water flooding, the oil film remains on the rock wall. At this time, the forces are balanced, and the combined force is zero. When the gas enters the seepage channel, the low viscosity of the gas decreases the resistance of the seepage channel, and so the flow velocity $v_{w}$ of the water increases. According to Newton's internal friction law, the shear stress $F \tau w$ of the injected water on the oil film increases, breaking the balanced forces of the oil film during water flooding and peeling the oil film off. The process of oil film peeling is shown in Fig. 12.

Under the condition of miscible flooding, the injected gas (such as $\mathrm{CO}_{2}$ ) penetrates the water film and dissolves in crude oil. The volume of the crude oil expands, the $\mathrm{CO}_{2}$ extracts the light components of crude oil into the gas phase, and finally condenses into oil film on the surface of the water film to form a flowable oil film. This achieves the effect of peeling the oil film off the pore walls (Cui et al., 2017).

(2) Cluster and columnar residual oil mobilization mechanism

The columnar residual oil is mainly caused by the heterogeneity of the rock pores, and the cluster residual oil is contiguous columnar remaining oil. The mobilization mechanism of the two is similar, and so the main mechanism is explained by taking the columnar remaining oil as an example.

In small pores, analysis of the force balance of the oil droplets shows that the columnar remaining oil is mainly affected by the additional resistance $p_{c 2}-p_{c 1}$ and displacement
Solid

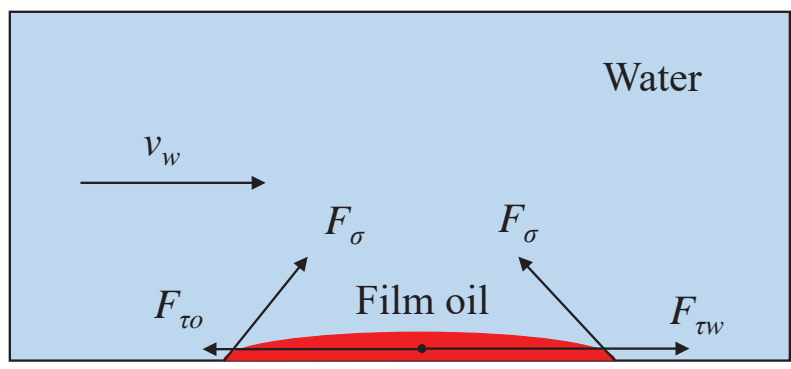

(a) Water flooding
Solid

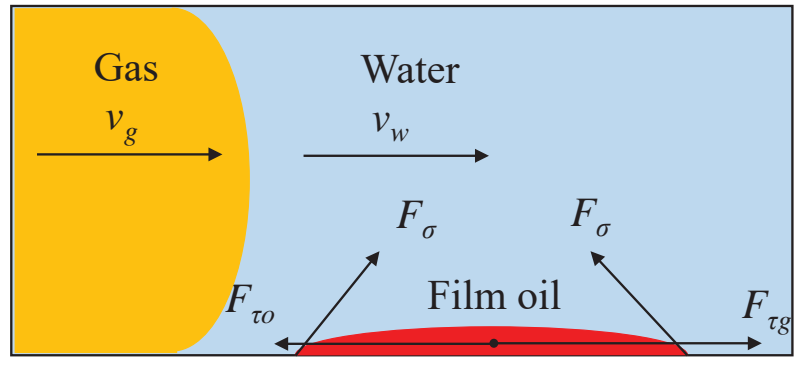

(b) Gas flooding

Fig. 11. Force of film residual oil on the oil-wet rock.
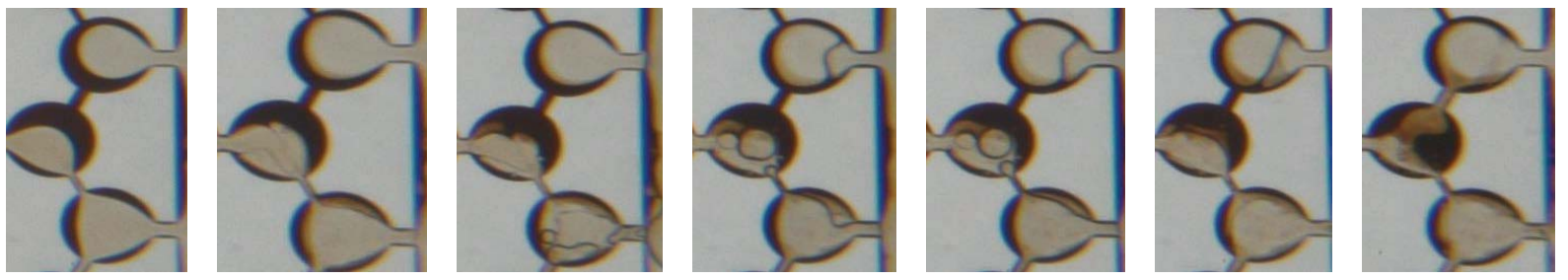

Fig. 12. Process of stripping off film residual oil after gas injection. 


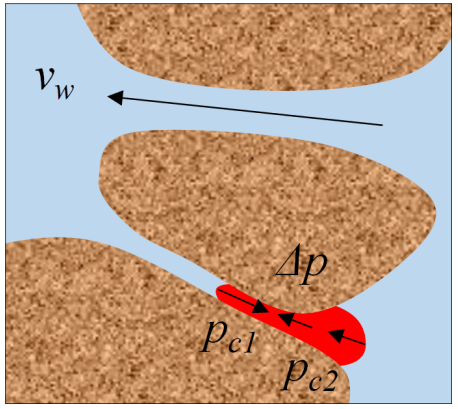

(a) Water flooding

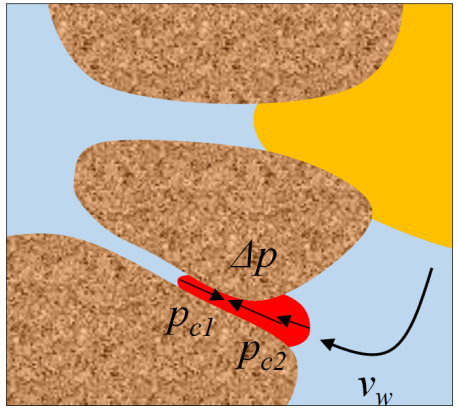

(b) Gas flooding

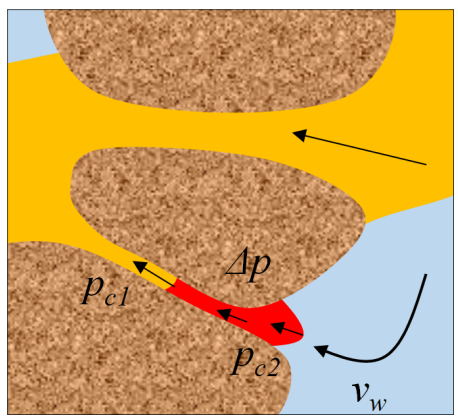

(c) Water flooding after gas flooding

Fig. 13. Forces of columnar residual oil at different stages.
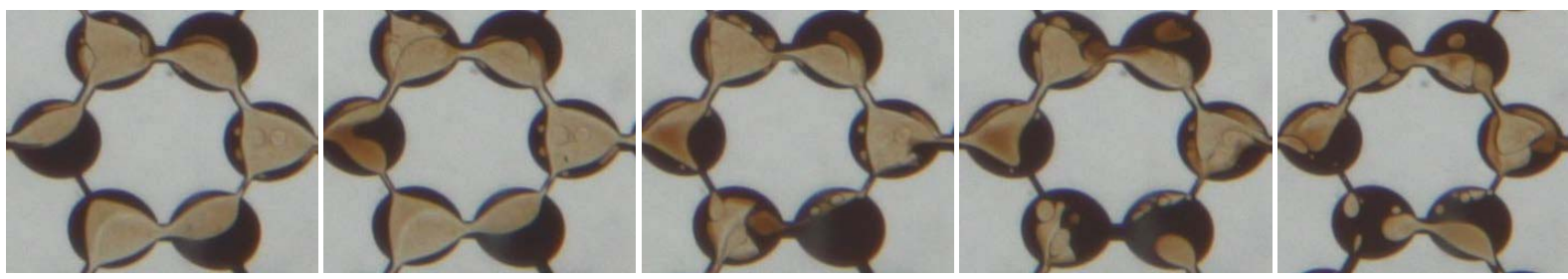

Fig. 14. Process of displacement of columnar residual oil after gas injection.

pressure $\Delta p$ due to the Jamin effect.

In the water flooding stage, there is columnar residual oil in both small pores and large pores. The injected water forms the dominant seepage channel in the large pores, and the displacement pressure acting on the columnar residual oil is less than or equal to the additional resistance, $\Delta p-$ $\left(p_{c 2}-p_{c 1}\right)=0$, as shown in Fig. 13(a). In the gas injection stage, the injected gas first enters the high-water-cut pores with small seepage resistance; at this point, the deformation ability of the bubbles is strong. A large additional resistance is formed when passing through the large pores, thereby increasing the local displacement pressure. At this time, the combined force of the columnar residual oil is $\Delta p-\left(p_{c 2}-p_{c 1}\right)>0$, and the columnar residual oil is activated, as shown in Fig. 13(b). The second startup mode of columnar residual oil is shown in Fig. 13(c). At this time, the gas undergoes a compressionrelease process when passing through the large pores, forming a local pressure disturbance and changing the force balance of the columnar residual oil. As the gas passes through the large pores, it is squeezed into the small pores and the front end of the columnar residual oil changes from water to gas. Thus, the capillary force of the gas-oil becomes more powerful. The combined force of the columnar residual oil is $\Delta p-p_{c 2}+p_{c 1}>0$, and the columnar residual oil starts to be displaced. The process of displacing the columnar residual oil is shown in Fig. 14.

\section{(3) Island residual oil mobilization mechanism}

Most of the island-shaped residual oil comes from the flow around the two sides of the water injected through the pores, as this does not form an effective driving force. The form of this residual oil is shown in Fig. 15. For the first type, the injected water goes from flowing in one channel to flowing in two channels. Under the condition of the same resistance in both channels, the island-shaped oil is retained in the pores because the same viscous shear force is acting in the two directions. After the gas passes through the throat, the pressure is released, and the interfacial tension between gas and oil is low. At this point, the island-shaped residual oil stretches and becomes longer. Finally, the force balance is broken, so the island of remaining oil forms. The second type of residual oil can be considered as a residual oil film, and its starting mechanism is the same as that of film residual oil. Fig. 16 shows the process of islanded residual oil being displaced.

(4) Dead-end (corner) residual oil mobilization mechanism

The dead-end (corner) residual oil mainly exists in dead ends or corners, which the injected water cannot always reach. As shown in Fig. 17, there is no effective force on the flow direction of the dead-end residual oil during water flooding. However, when the gas enters the pores, the shape of the dead-end residual oil changes due to the expansion of the compressed gas at the dead end. The viscous shear force and interfacial tension of the injected fluid overcome the viscous force of the oil, squeezing it from the dead end. The displacement of the remaining oil in dead ends under the condition of immiscible flooding is shown in Fig. 18.

As shown in Fig. 19, the injected gas (e.g., $\mathrm{CO}_{2}$ ) penetrates the water film under the condition of miscible flooding, and dissolves in the dead-end residual oil. Thus, the volume of the crude oil increases and it is squeezed out of the dead end. At the same time, the light components of the crude oil are extracted by $\mathrm{CO}_{2}$ into the gas phase. Finally, the flowing oil film condenses on the surface of the water film, achieving the effect of displacing the dead-end residual oil (Cui et al., 2017).

The mobilization mechanisms of different types of microscopic residual oil are summarized in Table 3. 


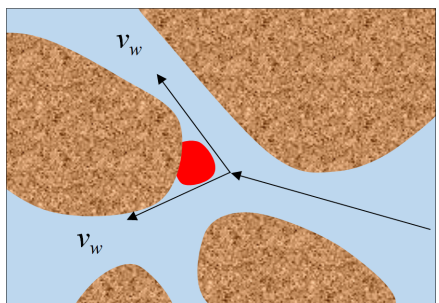

(a)

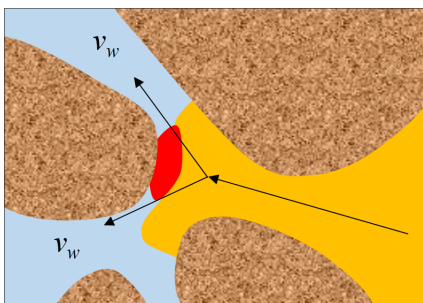

(b)

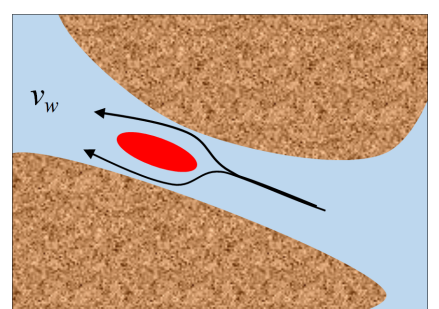

(c)

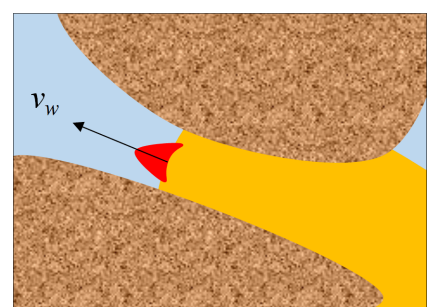

(d)

Fig. 15. Forces on two kinds of island-shaped residual oil at different stages (a) First type of residual oil during water flooding; (b) first type of residual oil during gas flooding; (c) second type of residual oil during water flooding; (d) second type of residual oil during gas flooding.

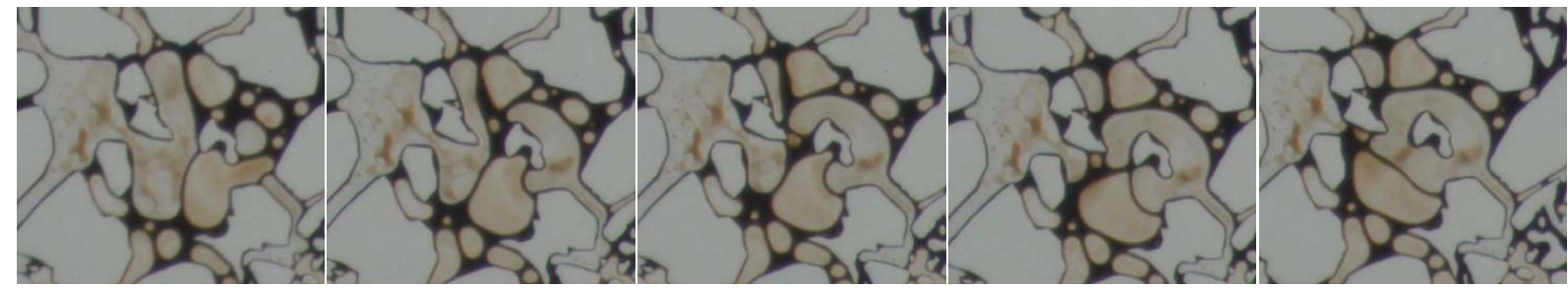

Fig. 16. Process of displacement of island-shaped residual oil after gas injection.

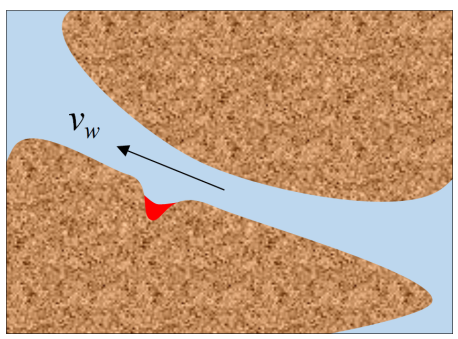

(a) Water flooding

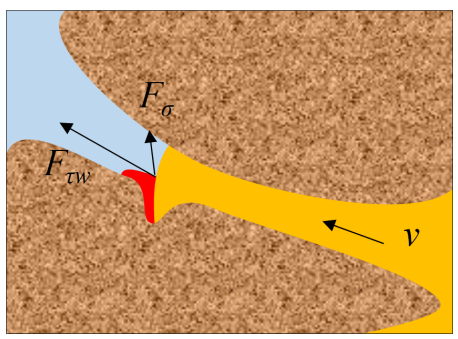

(b) Gas flooding

Fig. 17. Force of the dead-end residual oil at different stages.
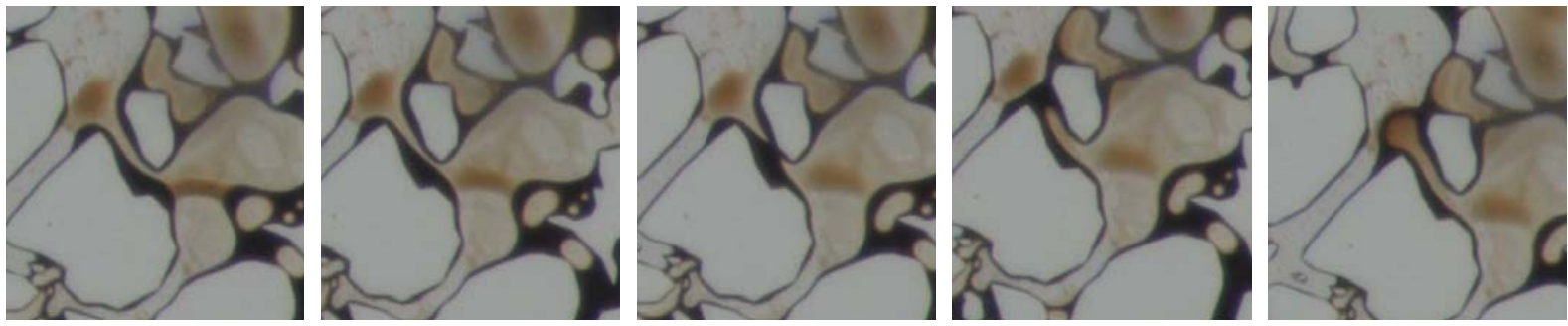

Fig. 18. Process of displacement of dead-end residual oil after immiscible gas injection.

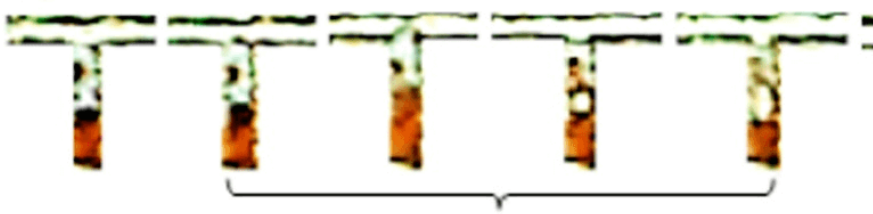

Dissolution

Oil swelling

(blue-water; brown-oil, colourless- $\mathrm{CO}_{2}$ )

Fig. 19. Process of displacement of dead-end residual oil after immiscible gas injection (Cui et al., 2017). 
Table 3. Mobilization mechanisms of different types of microscopic residual oil.

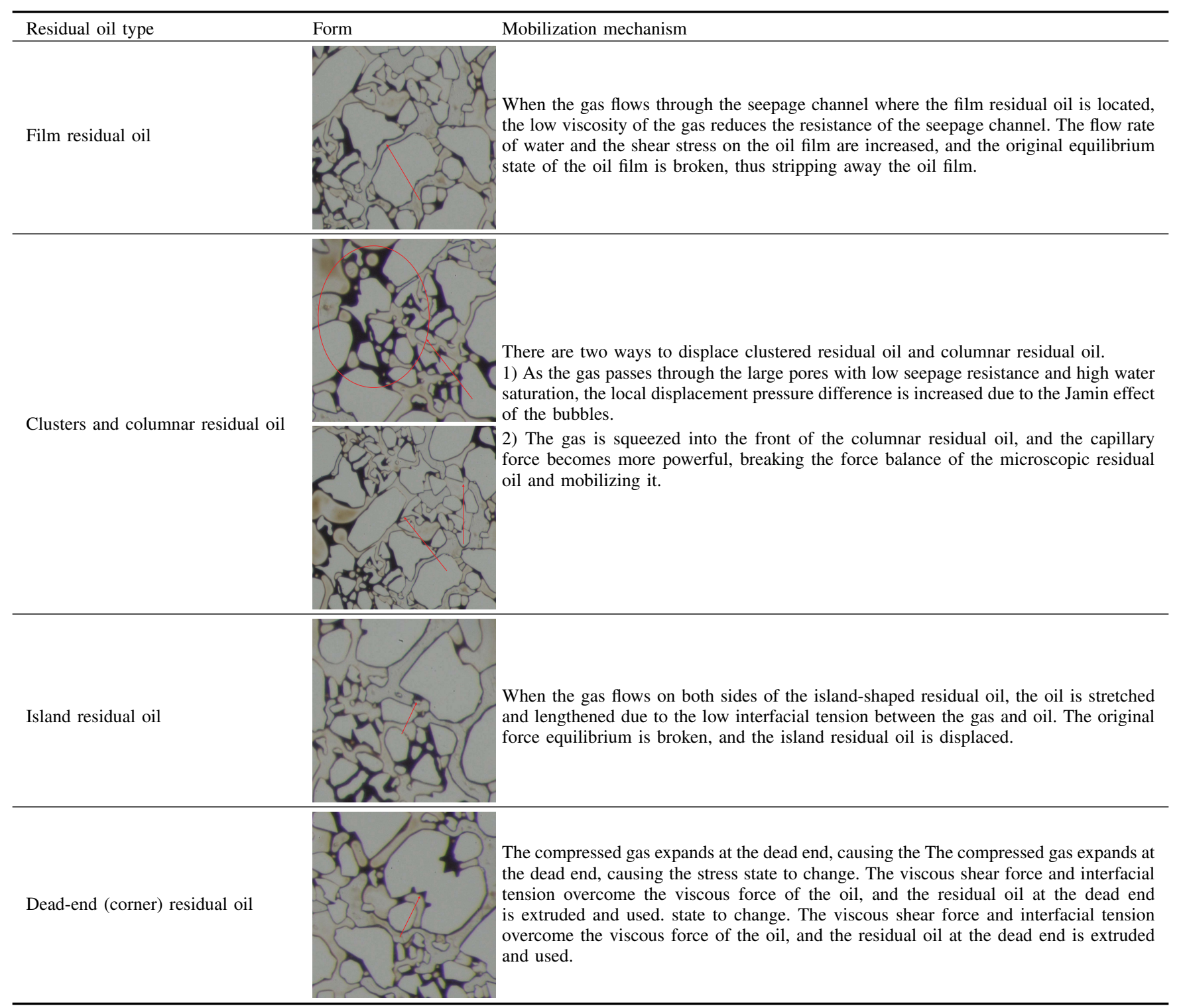

\subsection{Effect of injection parameters in WAG}

The effect of various injection parameters (i.e., IPV $(\mathrm{W}+\mathrm{G})$

Table 4. Effect of injection parameters on WAG flooding after water flooding.

\begin{tabular}{llllll}
\hline Exp & IPV & WAG ratio & Rfw, \% & EOR, \% & Rft, \% \\
\hline 2 & 0.3 & $2: 1$ & 38.47 & 15.62 & 54.09 \\
3 & 0.2 & $2: 1$ & 38.19 & 10.89 & 49.08 \\
4 & 0.4 & $2: 1$ & 38.21 & 13.41 & 51.62 \\
5 & 0.5 & $2: 1$ & 38.62 & 12.34 & 50.96 \\
6 & 0.3 & $1: 2$ & 37.54 & 10.41 & 47.95 \\
7 & 0.3 & $1: 1$ & 37.91 & 11.20 & 49.11 \\
8 & 0.3 & $3: 1$ & 38.56 & 12.31 & 50.87 \\
\hline
\end{tabular}

Note: Rfw- Waterflood recovery; EOR- Enhanced oil recovery; Rft- Total recovery of each cycle and the gas to water injection ratio) was examined through a series of core flooding experiments. The experimental results are presented in Table 4.

By comparing experiments 2-5, the optimized IPV (W+G) of each cycle can be determined. When the IPV of each cycle is small, the injected gas/water cannot form an effective continuous slug, and instead advances through the core as a continuous phase. If the IPV is greater than $0.3 \mathrm{PV}$, the gas channeling becomes more serious as the IPV increases, and the sweep efficiency of the injected gas is lower.

By comparing experiment 2 with experiments 6-8, the optimized WAG ratio can be identified. When the gas/water ratio is $2: 1$, WAG gives the most enhanced recovery. If the WAG ratio is high, the phenomenon of channeling becomes a serious issue. A reasonable gas/water ratio can effectively control the mobility of the injected fluid and ensure the stability of the displacement front. Under the experimental 
conditions, the optimal design parameters of WAG are an IPV $(\mathrm{W}+\mathrm{G})$ of $0.3 \mathrm{PV}$ in each cycle and a gas/water injection ratio of 2:1 This produces an EOR of $15.62 \%$.

\section{Conclusions}

Based on the experimental results obtained in this study, the following conclusions can be drawn:

1) Under the condition of residual oil after water flooding, $\mathrm{N}_{2}$-CGI can increase the rate of oil recovery by $5.27 \%$. $\mathrm{N}_{2}$-WAG in ultra-high water-cut reservoirs increases the displacement pressure, effectively expanding the sweep volume and improving the recovery efficiency by $15.62 \%$.

2) Gas moves through the waterflooded channels into the pore space previously occupied by water and residual oil, and then becomes a trapped gas. The injected gas can reduce residual oil saturation by displacing the residual oil into large waterfilled pores and blocking some water channels. WAG flooding decreases the free-gas saturation and increases the trapped-gas saturation significantly. After gas injection, the residual oil is mobilized as the force balance of the microscopic residual oil is broken.

3) The feasibility of the $\mathrm{N}_{2}$-WAG process is affected by many design parameters, such as the reservoir heterogeneity, fluid characteristics, WAG ratio, and IPV. An optimization experiment indicates that WAG flooding could achieve $15.62 \%$ EOR when the IPV $(\mathrm{W}+\mathrm{G})$ of each cycle is $0.3 \mathrm{PV}$ and the gas/water injection ratio is $2: 1$.

\section{Declaration}

Part of the content of this paper was previously accepted for presentation (We P11) at the IOR 2019-20th European Symposium on Improved Oil Recovery Conference, Pau, France, April 8-11, 2019 (https://doi.org/10.3997/22144609.201900176).

\section{Acknowledgement}

The authors acknowledge financial support from the Fundamental Research Funds for the Central Universities (Grant No. FRF-TP-20-006A1), the Open Fund of Sinopec Key Laboratory of Marine Oil \& Gas Reservoirs Production (2017), the National Science and Technology Major Project of China (Grant Nos. 2016ZX05010-003-001 and 2016ZX05025003-010), and the China Scholarship Council (Grant No. 201706440109). We also would like to express our thanks to Zengmin Lun and Hongmin Yu from SINOPEC Petroleum Exploration and Production Research Institute for sharing their knowledge on WAG-EOR field applications.

\section{Conflict of interest}

The authors declare no competing interest.

Open Access This article is distributed under the terms and conditions of the Creative Commons Attribution (CC BY-NC-ND) license, which permits unrestricted use, distribution, and reproduction in any medium, provided the original work is properly cited.

\section{References}

Afzali, S., Ghamartale, A., Rezaei, N., et al. Mathematical modeling and simulation of water-alternating-gas (WAG) process by incorporating capillary pressure and hysteresis effects. Fuel, 2020, 263: 116362.

Afzali, S., Rezaei, N., Zendehboudi, S. A comprehensive review on enhanced oil recovery by water alternating gas (WAG) injection. Fuel, 2018, 227: 218-246.

Akervoll, I., Talukdar, M. S., Midtlyng, S. H., et al. WAG injection experiments with in-situ saturation measurements at reservoir conditions and simulations. Paper SPE 59323 presented at the SPE/DOE Improved Oil Recovery Symposium, Tulsa, Oklahoma, 3-5 April, 2000.

Blunt, M. J. An empirical model for three-phase relative permeability. SPE Journal, 2000, 5(4): 435-445.

Christensen, J. R., Stenby, E. H., Skauge, A. Review of WAG field experience. SPE Reservoir Evaluation \& Engineering, 2001, 4(2): 97-106.

Cui, M., Wang, R., Lv, C., et al. Research on microscopic oil displacement mechanism of $\mathrm{CO}_{2}$ EOR in extra-high water cut reservoirs. Journal of Petroleum Science and Engineering, 2017, 154: 315-321.

DiCarlo, D. A., Akshay, S., Blunt, M. J. Three-phase relative permeability of water-wet, oil-wet, and mixedwet sandpacks. SPE Journal, 2000, 5(1): 82-91.

Fatemi, S. M., Sohrabi, M. Experimental and theoretical investigation of water/gas relative permeability hysteresis: Applicable to water alternating gas (WAG) injection and gas storage processes. Paper SPE 161827 Presented at the Abu Dhabi International Petroleum Conference and Exhibition, Abu Dhabi, UAE, 11-14 November, 2012.

Fatemi, S. M., Sohrabi, M. Experimental investigation of nearmiscible water-alternating-gas injection performance in water-wet and mixed-wet systems. SPE Journal, 2013, 18(1): 114-123.

Ghomian, Y., Pope, G. A., Sepehrnoori, K. Hysteresis and field-scale optimization of WAG injection for coupled $\mathrm{CO}_{2}$-EOR and sequestration. Paper SPE 110639 Presented at the SPE Symposium on Improved Oil Recovery, Tulsa, Oklahoma, USA, 19-23 April, 2008.

Guo, P., Huo, L., Jiang, B., et al. Parameter optimization of water alternating gas of Fang $48 \mathrm{CO}_{2}$ flooding pilot area. Journal of China University of Petroleum (Edition of Natural Science), 2012, 36(6): 89-93. (in Chinese)

Heiba, A. A., Davis, H. T., Scriven, L. E. Statistical network theory of three-phase relative permeabilities. Paper SPE 12690 Presented at the SPE Enhanced Oil Recovery Symposium, Tulsa, Oklahoma, 15-18 April, 1984.

Hoare, G., Coll, C. Effect of small/medium scale reservoir heterogeneity on the effectiveness of water, gas and water alternating gas WAG injection. Paper SPE 190855 Presented at the SPE Europec featured at $80^{\text {th }}$ EAGE Conference and Exhibition, Copenhagen, Denmark, 1114 June, 2018.

Itriago, Y. C., Araujo, M., Molinaris, J. Best practices for laboratory evaluation of immiscible WAG. Paper SPE 190303 Presented at the SPE Improved Oil Recovery Conference, Tulsa, Oklahoma, USA, 14-18 April, 2018. 
Janssen, M. T., Azimi, F., Zitha, P. L. Immiscible nitrogen flooding in bentheimer sandstones: Comparing gas injection schemes for enhanced oil recovery. Paper SPE 190285 Presented at the SPE Improved Oil Recovery Conference, Tulsa, Oklahoma, USA, 14-18 April, 2018.

Janssen, M. T., Torres Mendez, F. A., Zitha, P. L. Mechanistic modeling of water-alternating-gas injection and foamassisted chemical flooding for enhanced oil recovery. Industrial \& Engineering Chemistry Research, 2020, 59(8): 3606-3616.

Keller, A. A., Blunt, M. J., Roberts, A. P. V. Micromodel observation of the role of oil layers in three-phase flow. Transport in Porous Media, 1997, 26(3): 277-297.

Khanifar, A., Raub, M. R. A., Tewari, R. D., et al. Designing of successful immiscible water alternating gas (IWAG) coreflood experiment. Paper IPTC 18555 Presented at the International Petroleum Technology Conference, Doha, Qatar, 6-9 December, 2015.

Khorsandi, S., Li, L., Johns, R. T. Equation of state for relative permeability, including hysteresis and wettability alteration. SPE Journal, 2017, 22(6): 1915-1928.

Khorshidian, H., James, L. A., Butt, S. D. Pore-level study of the effect of miscibility and wettability on oil recovery during gas assisted gravity drainage. Paper SCA2017057 Presented at the Society of Core Analysts $31^{\text {st }}$ Symposium, Vienna, Austria, 27 August-1 September, 2017.

Kong, D., Li, Y., Yu, M., et al. Experimental investigation on block and transport characteristics of foam in porous media for enhanced oil recovery processes. Colloids and Surfaces A: Physicochemical and Engineering Aspects, 2019, 570: 22-31.

Kong, D., Lian, P., Zhu, W., et al. Pore-scale investigation of immiscible gas-assisted gravity drainage. Physics of Fluids, 2020, 32(12): 122004.

Kulkarni, M. M., Rao, D. N. Experimental investigation of miscible and immiscible Water-Alternating-Gas (WAG) process performance. Journal of Petroleum Science and Engineering, 2005, 48(1-2): 1-20.

Li, B., Li, Y., Kong, D., et al. Research on influence factors and screening method of tight sandstone oil reservoir $\mathrm{CO}_{2}$ huff and puff based on multi-index. Chemical Engineering Transactions, 2016, 55: 343-348.

Liu, H., Zhu, Z., Patrick, W., et al. Pore-scale numerical simulation of supercritical $\mathrm{CO}_{2}$ migration in porous and fractured media saturated with water. Advances in GeoEnergy Research, 2020, 4(4): 419-434.

Liu, Z., Liang, Y., Wang, Q., et al. Status and progress of worldwide EOR field applications. Journal of Petroleum Science and Engineering, 2020, 193: 107449.

Long, L., Li, Y., Gong, H., et al. Investigation of pressure drop of trapped oil in capillaries with circular crosssections. Industrial \& Engineering Chemistry Research, 2018, 57(41): 13866-13875.

Motealleh, M., Kharrat, R., Hashemi, A. An experimental investigation of water-alternating- $\mathrm{CO}_{2}$ coreflooding in a carbonate oil reservoir in different initial core conditions. Energy Sources, Part A: Recovery, Utilization, and
Environmental Effects, 2013, 35(13): 1187-1196.

Oren, P. E. Pore-Scale network modelling of waterflood residual oil recovery by immiscible gas flooding. Paper SPE 27814 Presented at the SPE/DOE Improved Oil Recovery Symposium, Tulsa, Oklahoma, 17-20 April, 1994.

Oren, P. E., Billiotte, J., Pinczewski, W. V. Mobilization of waterflood residual oil by gas injection for water-wet conditions. SPE Formation Evaluation, 1992, 7(1): 70-78.

Oren, P. E., Pinczewski, W. V. The effect of wettability and spreading coefficients on the recovery of waterflood residual oil by miscible gasflooding. SPE Formation Evaluation, 1994, 9(2): 149-156.

Pereira, G. G., Pinczewski, W. V., Chan, D. Y. C., et al. Porescale network model for drainage-dominated three-phase flow in porous media. Transport in Porous Media, 1996, 24(2): 167-201.

Piri, M., Blunt, M. J. Three-phase threshold capillary pressures in noncircular capillary tubes with different wettabilities including contact angle hysteresis. Physical Review E, 2004, 70(6): 061603.

Ramachandran, K. P., Gyani, O. N., Sur, S. Immiscible hydrocarbon WAG: Laboratory to field. Paper SPE 128848 Presented at the SPE Oil and Gas India Conference and Exhibition, Mumbai, India, 20-22 January, 2010.

Rücker, M., Bartels, W. B., Garfi, G., et al. Relationship between wetting and capillary pressure in a crude oil/brine/rock system: From nano-scale to core-scale. Journal of colloid and interface science, 2020, 562: 159169.

Shahverdi, H., Sohrabi, M., Fatemi, M., et al. Three-phase relative permeability and hysteresis effect during WAG process in mixed wet and low IFT systems. Journal of Petroleum Science and Engineering, 2011, 78(3-4): 732739.

Shahverdi, H., Sohrabi, M. Relative permeability characterization for water-alternating-gas injection in oil reservoirs. SPE Journal, 2016, 21(3): 799-808.

Singh, $\mathrm{H}$. Impact of four different $\mathrm{CO}_{2}$ injection schemes on extent of reservoir pressure and saturation. Advances in Geo-Energy Research, 2018, 2(3): 305-318.

Sohrabi, M. T. D. H., Tehrani, D. H., Danesh, A., et al. Visualization of oil recovery by water-alternating-gas injection using high-pressure micromodels. SPE Journal, 2004, 9(3): 290-301.

Sun, L., Wei, P., Pu, W., et al. The oil recovery enhancement by nitrogen foam in high-temperature and high-salinity environments. Journal of Petroleum Science and Engineering, 2016, 147: 485-494.

Valeev, A., Shevelev, A. Design of WAG parameters. Paper SPE 187843 Presented at the SPE Russian Petroleum Technology Conference, Moscow, Russia, 16-18 October, 2017.

Wang, L., He, Y., Wang, Q., et al. Multiphase flow characteristics and EOR mechanism of immiscible $\mathrm{CO}_{2}$ water-alternating-gas injection after continuous $\mathrm{CO}_{2}$ injection: A micro-scale visual investigation. Fuel, 2020, 282: 118689. 
Wang, X., Yin, H., Zhao, X., et al. Microscopic remaining oil distribution and quantitative analysis of polymer flooding based on CT scanning. Advances in Geo-Energy Research, 2019, 3(4): 448-456.

Xu, F., Chen, Q., Ma, M., et al. Displacement mechanism of polymeric surfactant in chemical cold flooding for heavy oil based on microscopic visualization experiments. Advances in Geo-Energy Research, 2020, 4(1): 77-85.

Yang, H., Hu, L., Chen, C., et al. Synthesis and plugging behavior of fluorescent polymer microspheres as a kind of conformance control agent in reservoirs. RSC Advances, 2018, 8(19): 10478-10488.

You, Q., Wang, H., Zhang, Y., et al. Experimental study on spontaneous imbibition of recycled fracturing flowback fluid to enhance oil recovery in low permeability sandstone reservoirs. Journal of Petroleum Science and Engineering, 2018, 166: 375-380.

You, Q., Wen, Q., Fang, J., et al. Experimental study on lateral flooding for enhanced oil recovery in bottomwater reservoir with high water cut. Journal of Petroleum Science and Engineering, 2019, 174: 747-756.

Zhang, Y., Gao, M., You, Q., et al. Smart mobility control agent for enhanced oil recovery during $\mathrm{CO}_{2}$ flooding in ultra-low permeability reservoirs. Fuel, 2019, 241: 442450.

Zhu, W., Ma, Q., Song, Z., et al. The effect of injection pressure on the microscopic migration characteristics by $\mathrm{CO}_{2}$ flooding in heavy oil reservoirs. Energy Sources, Part A: Recovery, Utilization, and Environmental Effects, 2019, doi.org/10.1080/15567036.2019.1644399. (published online)

Zuo, L., Chen, Y., Zhou, D., et al. Three-phase relative permeability modeling in the simulation of WAG injection. SPE Reservoir Evaluation \& Engineering, 2014, 17(3): 326-339. 